\title{
Os desafios educativos da geração Net
}

\author{
Manuel Meirinhos \\ Instituto Politécnico de Bragança - Escola Superior de Educação
}

\begin{abstract}
Resumo
Neste trabalho faz-se uma caraterização da geração Net, partindo de uma reflexão da relação do Homem com as tecnologias. Abordam-se os desafios que a geração Net coloca aos sistemas educativos atuais e em concreto à aprendizagem escolar. Abordam-se alguns métodos e teorias emergentes que procuram ir de encontro às necessidades educativas das novas gerações, que poderão contribuir não apenas para uma inovação incremental, mas também iniciar o processo de uma inovação transformativa dos sistemas escolares.
\end{abstract}

\section{Introdução}

Várias designações têm surgido para tentar caracterizar as gerações nascidas depois do surgimento da internet. As formas de comunicação e o acesso à informação alteraram-se nestas duas últimas décadas. As crianças desenvolvem as suas estruturas mentais integrando as tecnologias. Desenvolvem capacidades e caraterísticas psicológicas próprias. Vivem num mundo digital, enquanto a escola as procura atrair para um mundo analógico. Este confronto entre dois mundos requer reflexão e investigação a fim de conhecer melhor os contextos em que se podem educar as crianças no futuro. Com estre trabalho procura-se caraterizar o contexto tecnológico da geração Net, bem como identificar um conjunto de métodos ou teorias que parecem evidenciar-se na educação escolar dos nativos digitais. Neste sentido faz-se uma reflexão sobre o Homem perante a tecnologia, carateriza-se a geração Net, reflete-se sobre os novos desafios que esta geração coloca e sua relação com a função da escola, apresentam-se algumas teorias e métodos emergentes e por fim faz-se uma reflexão conclusiva.

\section{O Homem perante a tecnologia}

A relação do ser humano com a tecnologia é complexa. (...) ao contrário dos animais o ser humano transforma o seu ambiente, adaptando-o às suas necessidades, às reais e às socialmente induzidas, mas termina transformando-se a si próprio e à sociedade. Neste sentido podemos dizer que somos o produto das nossas próprias criações (Adell, 1997).

Para McLuhan, qualquer tecnologia é uma extensão de nós próprios, dos nossos próprios sentidos. Enquanto extensões de nós próprios, qualquer tecnologia, exterioriza, amplifica e modifica muitas funções cognitivas. Nesta visão das coisas, o computador, enquanto extensão do sistema nervoso central, amplifica a nossa capacidade intelectual. As mudanças cognitivas podem não ser rápidas e demorar algum tempo a perceberem-se. Segundo a abordagem sociocultural, os processos cognitivos superiores do homem são possíveis devido à interação constante que as nossas "ferramentas" cognitivas exercem com o ambiente. Os processos cognitivos implicam a existência de "ferramentas" mediadoras para pensar. O desenvolvimento da mente depende dos instrumentos culturais que utilizamos. Assim, a linguagem e os sucessivos sistemas de alfabetização tem configurado o nosso intelecto. Utilizamos as tecnologias para amplificar os nossos sentidos e capacidades. A sua influência é tal, que altera o que sabemos, a forma como pensamos, a forma como vemos o mundo e como nos relacionamos, como atuamos e como aprendemos. Aquilo que sabemos depende das tecnologias que utilizamos. À medida que as utilizamos em determinados contextos socioculturais, vamos apropriando-nos delas, internalizando-as, vão fazendo parte de nós, como uma segunda natureza, ao ponto de se tornarem invisíveis e não nos apercebemos delas. A singularidade da época que estamos a viver com o desenvolvimento das redes de comunicação digital é, por muitos autores, relacionada com outras épocas de evolução da humanidade, como o surgimento da linguagem, a criação da escrita ou o desenvolvimento da imprensa.

\section{A geração Net}

A geração Net (Tapscott, 1997) é a geração de crianças que nasceram depois de 1995, com o advento da internet. Esta data foi também adotada por autores como Bassiouni \& Hackley (2014). Têm surgido várias datas e designações para caraterizar as crianças que nasceram com o desenvolvimento da internet. Entre as mais divulgadas encontra-se a de "nativos digitais" (Prensky, 2001) e geração Z (Zapping) e geração Net, mas também existem outras como e-generation, Homo sapiens digitalis, etc. Considerando uma geração de pessoas, como sendo aquelas que crescem e desenvolvem as suas estruturas mentais num contexto social e tecnológico comum, a geração Net, é a primeira geração de crianças que teve acesso em larga escala (nas primeiras etapas de desenvolvimento) às tecnologias de informação digital, tais como telemóveis com aceso à internet, Wi-Fi a partir de vários dispositivos, jogos interativos a partir de vários dispositivos e serviços instantâneos de mensagens e socialização online em redes sociais. São crianças sempre em rede a partir de dispositivos móveis como telemóveis, tablets, IPAD, computadores portáteis e habituadas a uma evolução tecnológica constante. É a geração que assistiu ao declínio da televisão como meio de entretenimento e à desatualização de tecnologias como o MP3, o CD e o 
DVD. Estão sempre ligados e desenvolveram as suas estruturas mentais em presença dessas tecnologias digitais.

A internet veio provocar uma verdadeira revolução no mundo da informação e do conhecimento. As páginas pessoais, os blogs, as wikis e as redes sociais, criaram a infraestrutura necessária para os jovens passarem a dispor de um meio que lhes permite a expressão fácil e a colocação online de informação pouco relevante cientificamente não validada. Os buscadores de informação, como o Google, fizeram com que qualquer aluno tenha instantaneamente, uma superabundância de informação sobre qualquer tema, a partir de qualquer dispositivo móvel ligado à internet. $\mathrm{O}$ acesso à informação na era da internet é bastante diferente do acesso à informação no mundo analógico. Não foi apenas o acesso que se alterou, mas também a quantidade e a velocidade a que essa informação se produz e se disponibiliza. Vivemos numa época onde existe superabundância de informação para qualquer tema escolar e, os alunos podem não possuir competências para lidar de forma correta com esse "mar" de informação.

Existe uma grande quantidade de recursos, materiais, artigos, multimédia, livros, revistas especializadas online, bases de dados, portais temáticos, etc., acessíveis através da internet, a maioria dos quais não estão acessíveis desde outro espaço ou canal. A facilidade e comodidade de acesso aos mesmos e a gratuitidade da maior parte deles são sem dúvida fatores de grande ajuda para qualquer um que deseje consultar informação com finalidades académicas e, de certa forma, não se concebe hoje em dia um trabalho académico, o planeamento de uma investigação, a ampliação de conteúdos de uma disciplina, o trabalho para uma aula, etc., sem contar com a ajuda da internet como elemento de consulta (Comas e Sureda, 2007, s/p).

É a geração dos alunos digitais, mas na escola subsistem num mundo essencialmente analógico. Diminuíram a sua capacidade de escrita, e de pensamento abstrato. Desenvolvem as suas estruturas mentais a lidar com imagens, fortalecendo o hemisfério direito em detrimento do hemisfério esquerdo. Por vezes fazem uso menos consciente da tecnologia.

\section{Desafios educativos}

Ao alterar-se o quadro sociotécnico analógico de referência alteram-se ou desvanecem-se também as competências, as regras com que atuamos, os valores que utilizamos e os hábitos que sustentavam os nossos modos de aprender, de comunicar e de trabalhar. Desta alteração sentimos hoje o choque cultural entre muitos pais e professores analógicos e crianças digitais. Do novo contexto sociotécnico devem surgir novos valores, novas regras e uma nova ética que é necessário construir. Em 1958, Aldous Huxley (autor do admirável mundo novo) em entrevista a Mike Wallace alertava já para esta faceta das tecnologias: "O que eu acho é que não devemos ser apanhados de surpresa pelo avanço da nossa tecnologia. Isto aconteceu vezes sem conta na História com o avanço tecnológico, que por sua vez muda as condições sociais, e de repente as pessoas encontram-se em situações que não anteciparam e a fazer todo o tipo de coisas que, afinal, nunca quiseram fazer." Mais recentemente vários autores têm abordado esta questão menos consciente da utilização das tecnologias. Postman (1994) chama-nos à atenção não apenas para o que podemos fazer com a tecnologia, mas também para o que a tecnologia pode fazer de nós. Segundo o mesmo autor, a tecnologia não é neutra, devemos ter em atenção o determinismo tecnológico e a ausência de valores na utilização das tecnologias. $O$ espetacular avanço tecnológico põe em causa as bases em que assentava a cultura humana. Sartori (1998) falanos da emergência de um ser simbólico com diminuição da capacidade de abstração por primazia da imagem sobre a palavra, o que conduzirá a uma diminuição da racionalidade.

Um dos desafios que a escola enfrenta relaciona-se coma utilização consciente das tecnologias. Quem está atento aos problemas educativos da sociedade atual apercebe-se facilmente que uma das grandes problemáticas se relaciona com a questão da utilização consciente e crítica das tecnologias. Os alunos da geração Net, apesar de serem rápidos na utilização da tecnologia, necessitam desenvolver competências de literacia digital. Ou seja, não podemos apenas "educar com as tecnologias", mas também temos de "educar para as tecnologias". Da utilização menos consciente das tecnologias surgem, hoje, várias problemáticas associadas. Se por um lado temos o problema da segurança dos dados informáticos, relacionada com a segurança da informação que temos no computador sujeita a vírus, adware e spiwares, temos por outro lado, a segurança pessoal, relacionada com contactos com estranhos, roubo de identidade, phishing, compras online, etc. Outra problemática relaciona-se com a utilização excessiva das tecnologias e os perigos da viciação, nomeadamente em jogos online. A questão da utilização excessiva das tecnologias transporta-nos para as questões da mediatização tecnológica. Cada vez mais as crianças conhecem a realidade através de instrumentos técnicos. O instrumento técnico funciona sempre como um filtro, que pode ser deformante. Esta realidade mediatizada não deixa de ser real, mas é uma realidade virtualizada ou uma realidade cada vez mais simulada pelo instrumento técnico. A preferência pelo mundo simulado pode passar a ser a norma. É o "fim da rua" como espaço de brincadeira (Espanha, 2012) e, a emergência do quarto como espaço de divertimento e interação com o mundo exterior. Um dos aspetos importantes, mas que tem sido pouco estudado é efeito da publicidade da internet nas crianças. Da existência de muitos estudos sobre os efeitos da publicidade televisiva, assistimos agora a uma quase ausência de estudos na era da publicidade na internet. Para além da publicidade por mail e por SMS, muitos sites estudam os hábitos e os gostos dos utilizadores da internet, através de cookies e outros programas informáticos e a publicidade é dirigida às preferências dos utilizadores. Muitas vezes a publicidade é enganosa ou está dissimulada, as crianças são mais facilmente sugestionáveis e a publicidade na internet é, de 
momento, um "mundo" sem regulamentação.

Outra problemática bastante atual é a prática do ciberplágio nos trabalhos escolares. Muito baseado na falta de regras de utilização da internet, o ciberplágio é assim uma prática de desonestidade intelectual, não apenas baseada na apropriação indevida de informação através do copy-paste, mas também na apropriação indevida de trabalhos já elaborados, ou na compra parcial ou total de trabalho através da internet. Como refere Comas e Sureda (2007) o plágio atual, sobretudo o académico, dispõe de novas formas, meios e facilidades. Por essa razão as repercussões e profundidade são novas e parecem mais perigosas do que foram no passado. A utilização da internet requer regras, valores e uma forte dimensão ética, para a qual os nativos digitais não parecem estar preparados.

\section{A função da escola}

Pelo menos em teoria um dos desígnios da escola tem sido fazer com que os alunos aprendam com as tecnologias, ou seja aprender com os meios. Hoje não parece haver dúvida de que tecnologia e aprendizagem são inseparáveis. No entanto, a escola, tem estado bastante afastada da faceta de educar para aos meios, ou seja a utilização consciente das TIC. A utilização destas requer regras, valores e uma forte dimensão ética (Meirinhos, 2013). Esta faceta tem estado completamente ausente da educação dos nativos digitais. Não basta educar com, é necessário educar para os meios. Com a utilização menos consciente das tecnologias o aluno prejudica-se a si mesmo, uma vez que, deixa de desenvolver competências de escrita e a capacidade de fazer análises e sínteses, necessárias para o pensamento lógico e estruturado. A capacidade de ler analisar e sintetizar ideias de vários autores para depois articular esses conteúdos num novo texto próprio, é uma capacidade importante para o desenvolvimento da competência crítica e deveria ser valorizada no meio escolar.

A escola atual, com a sua organização, os seus modos de funcionamento, os seus espaços e tempos de aprendizagem pode não estar capacitada para dar resposta aos desafios da educação colocados por esta nova geração. Sabemos hoje que se podem fazer melhoramentos pedagógicos com inovação icremental, suportados por tecnologias emergentes. Aliás sabemos que existe projetos e ações de integração curricular das TIC inovadoras mas que têm muita dificuldade em perdurar no tempo. Frequentemente estão dependentes da duração do projeto ou da ação de investigação. Também sabemos que a pedagogia pode ser aumentada pela tecnologia quando os processos de aprendizagem se fundamentam em teorias de aprendizagem de raiz construtivista ou socioconstrutivista, como a teoria da flexibilidade cognitiva, teoria da cognição repartida ou distribuída, teoria da aprendizagem social e o conectivismo. Todas estas teorias têm servido para fundamentar a introdução das tecnologias digitais em contextos de aprendizagem presenciais ou a distância. Também sabemos hoje que a aprendizagem escolar não pode estar confinada ao interior dos quatro muros da escola. As redes de aprendizagem digital permitem expandir a aprendizagem escolar muito para além dos seus muros. A interação e colaboração a distância é hoje uma realidade e são necessárias novas abordagens pedagógicas para poder tirar proveito educativo da comunicação e acesso à informação virtualizada.

\section{A emergência de diferentes abordagens}

Diferentes teorias ou modelos têm surgido recentemente, procurando fundamentar a utilização das tecnologias digitais em contextos de aprendizagem, que colidem frequentemente com a estrutura organizativa e de funcionamento das instituições educativas. Descrevemos a seguir essas abordagens.

\section{O conectivismo}

O conectivismo é uma teoria desenvolvida por Siemens para contextos específicos de aprendizagem em rede. Siemens (2004), ao desenvolver o conectivismo apresenta-o como uma teoria de aprendizagem adaptada à sociedade do conhecimento, onde a aprendizagem já não é tanto de cariz individual, mas assenta na circulação da informação pelos vários nós espalhados pela rede, que permite a construção e reconstrução do conhecimento.

"O ponto de partida do conectivismo é o indivíduo. $\mathrm{O}$ conhecimento pessoal é composto por uma rede, que alimenta as organizações e instituições, que por sua vez realimentam a rede, e depois continuam a proporcionar aprendizagem ao indivíduo. Este ciclo de desenvolvimento do conhecimento (pessoal - rede organização) permite que os alunos se mantenham atualizados, através das conexões que formaram" (Siemens, 2004, s/p).

Devido à facilidade de acesso à informação e com o emergir do conhecimento em rede, os indivíduos dependem cada vez mais das conexões que criam para se manterem atualizados.

Para este autor, a aprendizagem deve ser baseada em modelos de rede de aprendizagem centrados no aluno, e não nos modelos tradicionais centrados no professor, onde o aluno através das várias conexões da rede, estabelece relações com os colegas e especialistas de todo o mundo, podendo consultar conteúdos académicos diferentes, proporcionando um leque variado de recursos, sob diferentes pontos de vista, descobrindo, construindo e partilhando o conhecimento.

\section{O Flipped Classroom}

O Flipped Classroom ou sala de aula invertida não é um modelo novo mas está a ganhar força na comunidade educativa e a crescer de forma exponencial (Carvalho \& Ramos, 2015). Com esta metodologia as TIC são úteis para a realização de tarefas, resolver problemas ou desenvolver projetos, transformando o aprendiz em investigador e responsável ativo da sua aprendizagem. Este modelo defende que o aluno deve fazer toda a observação e análise em casa recorrendo a 
material digital disponibilizado pelo professor e outro existente na Web e, na sala de aula, partilhar e discutir o conhecimento com os colegas. O professor passa a estratega que ajuda na formulação e consolidação dos conceitos e competências.

Devido à facilidade de acesso à informação e com o emergir do conhecimento em rede, os indivíduos dependem cada vez mais das conexões que criam para se manterem atualizados.

"Novas capacidades são exigidas como pesquisar, seleccionar e citar; cooperar e colaborar presencialmente e online; e, ainda, publicar e partilhar online. A diversidade de informação online bem como de actividades orientadas para a pesquisa, de exercícios de correcção automática, de simulações, de jogos, entre outros, constituem recursos a integrar nas práticas lectivas" (Carvalho, 2007, p.27).

Siemens (2008) considera que a aprendizagem, para além da aprendizagem formal, pode ocorrer através de jogos e simulações, de comunidades de prática, redes sociais, conferências, leituras, voluntariado, passatempos e, defende que a autoaprendizagem surge através do pensamento crítico e criativo.

Para este autor, a aprendizagem deve ser baseada em modelos de rede de aprendizagem centrados no aluno, e não nos modelos tradicionais centrados no professor, onde o aluno através das várias conexões da rede, estabelece relações com os colegas e especialistas de todo o mundo, podendo consultar conteúdos académicos diferentes, proporcionando um leque variado de recursos, sob diferentes pontos de vista, descobrindo, construindo e partilhando o conhecimento

\section{A autoregulação}

Existe um considerável corpo de informação cujas ideias suportam as evidências de que ajudar os alunos a desenvolver estratégias de autorregulação pode melhorar a eficácia dos seus métodos de aprendizagem (Zimmermen, 1994)

A autorregulação, um conceito que já não é novo, oriundo das teorias sociocognitivas da aprendizagem, refere-se ao controlo do indivíduo sobre si mesmo e sobre a sua aprendizagem (objetivos, planificação, estratégias de aprendizagem, etc.). Este conceito está associado ao conceito de autodireção no sentido do aluno ser capaz de dirigir o seu próprio percurso de aprendizagem, o requer competências metacognitivas, motivacionais e responsabilização pela aprendizagem. A capacidade de aprender autonomamente passa igualmente pelo desenvolvimento de estratégias de autorregulação. No dizer de Marcelo (2002), a autorregulação gera um estilo próprio de implicação na resolução das tarefas, estabelecendo as suas próprias metas, planeando as suas próprias estratégias para avaliar o grau de cumprimento das metas, processando informação e encontrando recursos para aprender. São estas características que permitem aprender ao longo de toda a vida e, conforme as circunstâncias, construir o itinerário formativo e a trajetória profissional.

\section{A coassociação}

Prensky apresentou recentemente um novo panorama pedagógico, baseado na coassociação, visando implicar mais os alunos na sua aprendizagem com as ferramentas digitais, reduzindo ou eliminando a apresentação de conteúdos, mas onde o professor com perguntas guia implica o aluno na aprendizagem. Este tipo de enquadramento pedagógico requer não apenas uma inovação incremental, mas sim uma inovação de disruptiva, com alteração dos processos de aprendizagem escolares. Para Prensky (2011) não há dúvidas que a tecnologia digital será cada vez mais importante na aprendizagem dos alunos, no entanto, não está completamente clara a forma de utilização. $\mathrm{Na}$ teoria da coassociação o trabalho do professor consiste em atuar como orientador e guia da utilização correta das TIC por parte dos alunos para a estimular a aprendizagem (Prensky, 2011). A coassociação inclui uma metodologia completamente oposta à aula expositiva. No processo de aprendizagem os alunos são responsáveis por: seguir os seus interesses; utilizar qualquer tecnologia disponível; investigar e compilar informação; responder a perguntas, partilhar ideias e informações; praticar, nomeadamente através de jogos; criar apresentações em texto e multimédia. Os professores devem responsabilizar-se pelo seguinte: Elaborar e fazer boas perguntas; assessorar os alunos; colocar o material curricular no contexto adequado; explicar de forma individual; criar rigor; assegurar a qualidade. Se através destes aspetos podemos vislumbrar algumas semelhanças com a estratégia Flipped cassroom, Prensky (2011) integra a coassociação na vertente pedagógica orientada pelos seguintes vetores: aprendizagem centrada no aluno; aprendizagem baseada em problemas; aprendizagem baseada em projetos; aprendizagem baseada em estudos de casos; aprendizagem baseada na investigação; aprendizagem ativa; aprendizagem construtivista e colaborativa; aprender fazendo.

Este tipo de enquadramento pedagógico requer não apenas uma inovação incremental, mas sim uma inovação de rutura, com alteração de todos os processos de aprendizagem escolares. Na Finlândia existem já experiências piloto e parece existir vontade política de até 2020 todas as escolas do sistema educativo funcionarem sem disciplinas. É uma abordagem centrada em tópicos multidisciplinares que integram o contributo de vários professores. É uma nova visão de escola mais orientada para a educação e para os processos criativos da geração Net.

\section{Conclusão}

A problemática da educação das novas gerações nascidas com o advento da internet tem merecido a atenção de muitos pensadores. Uma das inquietações presentes relaciona-se com o facto de como pode a escola atual, baseada em procedimentos do passado e essencialmente analógica, educar para o futuro as crianças que cresceram numa cultura digital. Este é um 
grande desafio para a escola. É certo que muitos professores e investigadores têm procurado a inovação pedagógica de suporte tecnológico. Não faltam experiências baseadas numa "aliança" entre a tecnologia e a pedagogia. Grande parte dessas inovações não perdura no tempo. Limitam-se normalmente ao período de duração da experiência ou da investigação. Existe nesta linha uma grande multiplicidade de experiências que conseguem uma inovação incremental ou de melhoramento, fundamentadas em teorias e raiz construtivista ou socioconstrutivista. Recentemente têm emergido teorias e modelos que procuram dirigir-se mais para as necessidades educativas dos nativos digitais, como sejam o conectivismo, o flipped classroom, a autorregulação e a coassociação. São teorias ou modelos que coincidentes em alguns aspetos e que podem configurar não apenas inovações incrementais mas estimular a inovação de rotura ou transformativa da escola para se adequar aos processos de aprendizagem dos nativos digitais. Alguns sistemas educativos, como o caso finlandês parecem já ter percebido esta perspetiva, ao abandonar os conteúdos disciplinares e ao trabalhar por tópicos interdisciplinares. Esta inovação transformativa poderá permitir integrar, de forma natural, as tecnologias digitais nos processos de aprendizagem na geração Net.

\section{Bibliografía}

Adell, L. (1997). Tendencias en educación en la Sociedad de la Información. Edutec-e. Revista Electrónica de Tecnología Educativa, nº 7.

Bassiouni, D. \& Hackley, C. (2014). 'Generation Z' children's adaptation to digital consumer culture: A critical literature review. Journal of Customer Behaviour, Vol. 13 (2), pp.113-133.

Carvalho, R. \& Silva, R. (2015). Flipped classroom Centrar a aprendizagem no aluno recorrendo a ferramentas cognitivas. Confereência Challenges 2015: Meio Século de TIC na Educação. Braga.

Comas, R. \& Sureda, J. (2007). Ciber-Plagio Académico. Una aproximación al estado de los conocimientos. Revista TEXTOS de la CiberSociedad, $\mathrm{n}^{\circ} 10$.
Espanha, R. (2012). Práticas da e-generation em portugal: resultados de estudos e questões contemporâneas. In Ponte, C.; Jorge, A.; Simões, A.; Cardoso, D. (Org). Crianças e internet em Portugal: Acessos, usos, riscos, mediações: Resultados do inquérito europeu EU Kids Online pp. 41-53. Coimbra: Minerva Coimbra.

Marcelo, C. (2002). La formación inicial y permanente de los educadores. In C. E. d. Estado (Ed.), Los educadores en la sociedad del siglo XXI (pp. 161-194). Madrid: Ministerio de Educación, Cultura y Deporte.

Meirinhos, M. (2013). Teachers and ICT skills: towards a new digital literacy. In Dias, P. and Bastos, A. (Org.) Plagiarism, Phenomenon in Europe: research contributes to prevention. Faculdade de Filosofia: Braga.

Postman, N. (1994). Tecnopólis. La rendición de la cultura a la tecnología. Valencia: Círculo de lectores.

Prenseky, M. (2011). Enseñar a nativos digitales. Madrid: Ediciones SM.

Prensky, M. (2001). Digital Natives, Digital Immigrants. On the Horizon. Vol. 9 (5), 1-6. http://dx.doi.org/10.1108/10748120110424816

Sartori, G. (1998). Homo videns. La sociedad teledirigida. Madrid: Santillana S. A.

Siemens, G. (2004). Connectivism: A Learning Theory for the Digital Age. International Journal of Instructional Technology and Distance Learning. Acedido em 4 de Novembro, disponível em http:// www.itdl.org/journal/jan_05/article01.htm

Siemens, G. (2008). New structures and spaces of learning: The systemic impact of connective knowledge, connectivism, and networked learning. Universidade do Minho, Encontro sobre Web 2.0. Acedido em 24 de Novembro, disponível em http://elearnspace.org/ Articles/systemic_impact.htm

Tapscott, D. (1997). Growing Up Digital: The Rise of the Net Generation. New York: Mcgraw-Hill

Zimmerman, B. (1994). Self-regulation of learning and performance: Issues and educational applications. Hillsdale, NJ: Erlbaum 